\title{
Comparative analysis of the effects of ultrasound-targeted microbubble destruction on recombinant adeno-associated virus- and plasmid-mediated transgene expression in human retinal pigment epithelium cells
}

\author{
XIAO-ZHI ZHENG ${ }^{1 *}$, YING WU ${ }^{1 *}$, HONG-LI LI ${ }^{1 *}$, LIAN-FANG DU ${ }^{1}$, HUI-PING WANG ${ }^{2}$ and QING GU $^{3}$ \\ ${ }^{1}$ Department of Medical Ultrasound, ${ }^{2}$ Experimental Research Center, ${ }^{3}$ Experimental Research Laboratory of Ophthalmology, \\ Shanghai Jiaotong University Affiliated First People's Hospital, Shanghai 200080, P.R. China
}

Received June 19, 2009; Accepted August 19, 2009

DOI: 10.3892/mmr_00000195

\begin{abstract}
Ultrasound-targeted microbubble destruction (UTMD) has been utilized to deliver a drug/gene into cells in both in vitro and in vivo studies. This study was performed to investigate the feasibility of UTMD-enhanced recombinant adeno-associated virus- (rAAV) and plasmid-mediated transfection into the human retinal pigment epithelium (RPE) cell line ARPE-19. Additionally, the transfection efficiency of rAAV and plasmid was compared in order to choose the appropriate gene vector or strategy to be used with UTMD for RPE-based gene modification. rAAV or plasmid encoding an enhanced green fluorescent protein gene was administered to ARPE-19 cells under various UTMD conditions. Cell viability was assessed by the 3-(4,5-dimethylthiazol-2-yl)-2,5diphenyltetrazolium bromide (MTT) assay. Transfection efficiency was determined by fluorescence microscopy and flow cytometry. UTMD significantly enhanced the transfection efficiency of rAAV and plasmid in ARPE-19 cells without adverse effects on cell viability. The transfection efficiency of rAAV was higher than that of plasmid. rAAV is therefore an appropriate gene vector for use with UTMD in retinal gene modification.
\end{abstract}

\section{Introduction}

In their physiological state, retinal pigment epithelium (RPE) cells play an indispensable role in retinal cell biology,

Correspondence to: Professor Lian-Fang Du, Department of Medical Ultrasound, Shanghai Jiaotong University Affiliated First People's Hospital, 85 Wujin Road, Shanghai 200080, P.R. China E-mail: du_lf@163.com.

${ }^{*}$ Contributed equally

Key words: ultrasound-targeted microbubble destruction, gene expression, recombinant adeno-associated virus 2, plasmid, ARPE-19 cells including the phagocytosis of shed rod outer segments and the physiological adhesion of neural retina, the transportation of nutrient, the removal of waste products, the secretion of growth factors and the maintenance of the blood-retinal barrier $(1,2)$. The degeneration of RPE is involved in a wide range of retinal diseases, including retinitis pigmentosa and age-related macular degeneration $(1,3)$. In such pathological states, the deterioration or disorder of RPE function eventually results in loss of vision. Since mature RPE cells do not proliferate in vivo and undergo growth only by means of cell enlargement (4), regenerative RPE-based therapies have been employed to repair the function of aberrant RPE. However, the poor viability of transplanted RPE cells limits their therapeutic efficacy. A potential alternative approach with the aim of improving RPE viability and therapeutic efficacy is gene modification.

To date, gene modification has not experienced extensive success. The two major determinants for the success of gene modification are the novel vector used and the feasibility of the gene delivery technique. Multiple viral and non-viral vectors have been investigated. Among the viral vectors, adenoassociated virus (AAV) is an attractive candidate for human gene modification due to its non-pathogenic nature (5) and its ability to infect a wide variety of cells, including ARPE-19. AAV typically provides long-term expression of foreign genes and does not induce inflammation or cytotoxicity (6). However, the transduction of AAV occurs with relatively low transduction efficiency in some tissues, which limits its therapeutic effectiveness. Among the commonly used non-viral vectors are naked plasmids. These are relative safe, have the capacity to transfer large genes, and are site-specific, non-inflammatory and non-toxic (7). Although naked plasmids are free of virusassociated adverse effects, their transduction efficiency is also low and their transgene expression is relatively poor.

Ultrasound-targeted microbubble destruction (UTMD) is a potential site-specific gene transfer modality that has been gradually developed over the past two decades. Studies have confirmed that UTMD can improve the cellular uptake of polynucleotides $(8,9)$, proteins $(10)$ and small-molecule drugs (11). Thus, it is regarded as a promising gene delivery technique for gene modification. 
In this study, we hypothesized that the intracellular delivery of rAAV- and plasmid-mediated transgene into human RPE cells by UTMD could lead to improvements in cellular function and viability. Consequently, the feasibility of UTMDenhanced rAAV and plasmid transfection into ARPE-19 cells was examined, and their transfection efficiency was compared in order to choose an appropriate gene vector or strategy for use with UTMD in RPE-based gene modification.

\section{Materials and methods}

Recombinant adeno-associated virus. The rAAV2-EGFP was purchased from Vector Gene Technology Company Ltd. (Beijing, P.R. China) and expressed the transgene under the control of the cytomegalovirus promoter.

Plasmid preparation. An expression vector for the EGFP gene, pEGFP-N1 (4.7 kb), was provided by the Experimental Research Center (Shanghai Jiaotong University Affiliated First People's Hospital, Shanghai, P.R. China). Plasmid DNA was purified from a culture of Escherichia coli DH5a using the EndoFree Plasmid Maxi Kit (Qiagen Inc., Valencia, CA, USA) following the manufacturer's protocol. The purity of the plasmid DNA was determined by measuring absorption at a 260-nm wavelength (A260) using spectrophotometry. The A260:A280 ratio of pEGFP-N1 was between 1.8 and 1.9, indicating that the purified DNA was free of proteins and RNA. All experiments were performed using the same preparation of plasmid DNA.

Microbubble contrast agents. SonoVue ${ }^{\circledR}$ microbubble contrast agent (Bracco, Milan, Italy) was reconstituted in saline solution according to the manufacturer's protocol, and yielded a preparation containing $2-5 \times 10^{8}$ microbubbles $(\mathrm{MBs}) / \mathrm{ml}$ by inversion/agitation of the unit. This microbubble contrast agent is a composition of a core of sulfur hexafluoride gas and an envelope of phospholipids. The average diameter of the MBs was 2.5-6.0 $\mu \mathrm{m}$.

Cell culture. The human RPE cell line ARPE-19 (ATCC, Rockville, MD, USA) was grown in Dulbecco's modified Eagle's medium (DMEM) (Gibco, Grand Island, NY, USA) supplemented with $10 \%$ fetal bovine serum (FBS) (Gibco) at $37^{\circ} \mathrm{C}, 5 \% \mathrm{CO}_{2} / 95 \%$ air.

Cell viability. The cell viability of ARPE-19 under the influence of UTMD was assessed with the 3-(4,5-dimethylthiazol-2-yl)2,5diphenyl-tetrazolium bromide (MTT) assay. A therapeutic ultrasound machine (Topteam 161, Chattanooga, TN, USA) and a $1-\mathrm{cm}^{2}$ probe were applied in this experiment. The ARPE-19 cells were seeded in 96-well plates at a density of $1 \times 10^{4}$ cells/ well and grown in a humidified incubator at $37^{\circ} \mathrm{C}, 5 \% \mathrm{CO}_{2} / 95 \%$ air for $24 \mathrm{~h}$. When the cells reached $70-80 \%$ confluence, the medium in each well was drawn off and replaced with $100 \mu \mathrm{l}$ fresh DMEM for the the control group, or with a 100- $\mu 1$ mixed solution of MBs and fresh DMEM (at MB concentrations of 20, 50 and $100 \%$ ) for use in the UTMD group. The frequency and pulse recurrent frequency (PRF) of the ultrasound (US) were set at $1 \mathrm{MHz}$ and $50 \mathrm{~Hz}$, respectively. Additional parameters of US irradiation were: intensity, 1, 2 and $3 \mathrm{~W} / \mathrm{cm}^{2}$; duration, 1, 2 and $4 \mathrm{~min}$; duty cycle, 50\%. For insonation, the probe was placed at the bottom of the plates with a small amount of coupling medium on its surface. A home-made plastic disc with a hole the same size as the wells in its middle was placed between the probe and the bottom of the plates to ensure the same thickness of coupling medium between the probe and the plates, and to prevent ultrasonic radiation from affecting consecutive wells. After US exposure, each well was supplemented with $100 \mu \mathrm{l}$ of DMEM, then the ARPE-19 cells were cultured for an additional $24 \mathrm{~h}$. Subsequently, $20 \mu 1$ of $5 \mathrm{mg} / \mathrm{ml}$ MTT solution in PBS was added to each well. After a 4-h incubation at $37^{\circ} \mathrm{C}, 5 \% \mathrm{CO}_{2} / 95 \%$ air, the supernatant was removed and the formazan product was washed out by treatment with $150 \mu \mathrm{l}$ dimethyl sulfoxide. The absorbance of each well was measured in an enzyme-linked immunosorbent assay reader at $570 \mathrm{~nm}$. Untreated cells served as the reference and were taken as $100 \%$ viability. The percentage of cell viability was calculated using the equation: cytoactive (\%) x optical density (OD) of the treatment group/OD of the control group x $100 \%$.

Experimental grouping. The ARPE-19 cells were placed in every other well of 24-well plates at a density of $2 \times 10^{5}$ cells/well and incubated in $500 \mu \mathrm{l}$ DMEM with $10 \% \mathrm{FBS}$ for $24 \mathrm{~h}$ prior to transfection. The cells were then respectively co-cultured with rAAV2-EGFP alone at a multiplicity of transfection (MOI) of $1 \times 10^{3}$ vector genomes per cell (vg/cell) (group R alone) or with pEGFP-N1 alone at a concentration of $10 \mu \mathrm{g} /$ well (group $\mathrm{P}$ alone), and in combination with MBs (group R+MBs and group $\mathrm{P}+\mathrm{MBs}$ ), US (group $\mathrm{R}+\mathrm{US}$ and group $\mathrm{P}+\mathrm{US}$ ) or UTMD (group $\mathrm{R}+\mathrm{US}+\mathrm{MBs}$ and group $\mathrm{P}+\mathrm{US}+\mathrm{MBs}$ ).

Ultrasound exposure. The above-mentioned therapeutic ultrasound machine and a $2-\mathrm{cm}^{2}$ probe were applied in this experiment. The parameters of UTMD were in accordance with those of the cell viability test ( 1 and $2 \mathrm{~W} / \mathrm{cm}^{2}$ intensity, 1 and 2 min duration, and $50 \%$ duty cycle). MB concentrations of $13.3,20,26.7,33.3,40,50$ and $100 \%$ were selected. Prior to US exposure, the DMEM in the 24-well plates was drawn out and a small amount of fresh serum-free DMEM was added to the medium, ensuring that the volume per well was $150 \mu 1$. rAAV2EGFP and pEGFP-N1 were diluted by DMEM and mixed with isovolumic MBs, then left standing for $5 \mathrm{~min}$. The final solution was added to the plates and exposed to US as described above. Each of the 24-well plates was supplemented with medium to a final volume of $500 \mu \mathrm{l}$ at $2 \mathrm{~h}$ post-transduction, and was replaced with fresh DMEM with $10 \%$ FBS $12 \mathrm{~h}$ after transfection.

Gene transfection efficiency. Following gene transfection, the ARPE-19 cells of the rAAV-EGFP and pEGFP-N1 groups were incubated in DMEM with 10\% FBS for $48 \mathrm{~h}$. EGFP expression was observed and photographed using inverted fluorescence microscopy (Zeiss Axiovert S100, Jena, Germany). EGFP expression of the transducted ARPE-19 cells was quantitatively examined by FCM analysis (EPICS XL, Beckman Coulter Co., Miami, FL, USA).

Statistical analysis. Data were expressed as the means and standard deviation (mean $\pm \mathrm{SD}$ ). Analysis of variance (ANOVA) was used to test for significance by multiple comparison. Differences were considered significant at $\mathrm{p}<0.05$. SPSS version 13 (SPSS, Chicago, IL, USA) was used for all statistical analysis. 
A

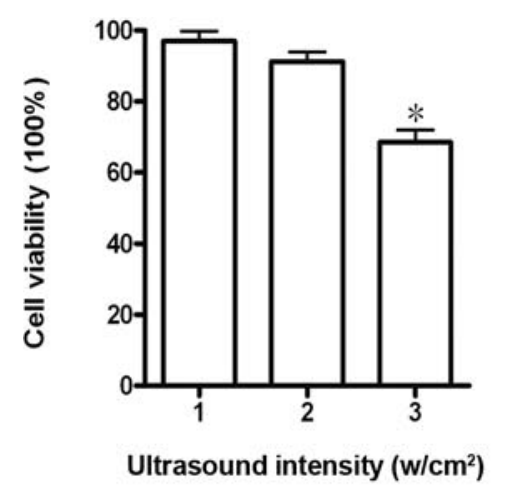

B

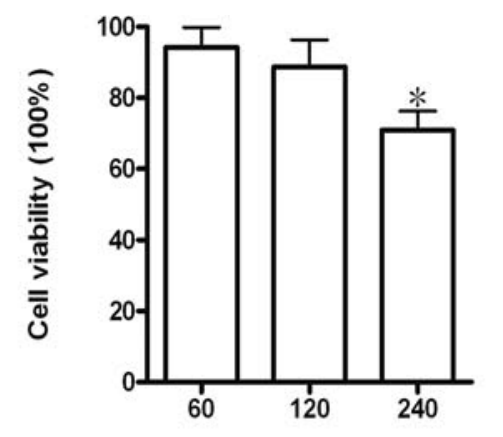

Ultrasound exposure time (sec)
C

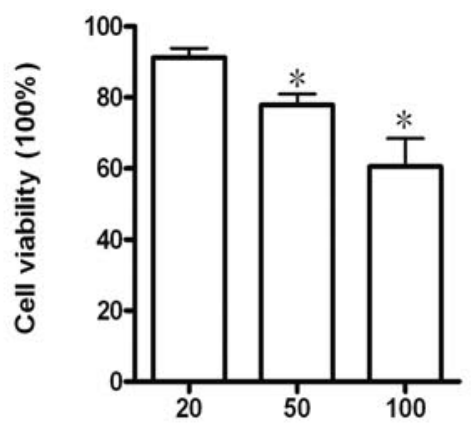

Microbubble concentration (\%)
D

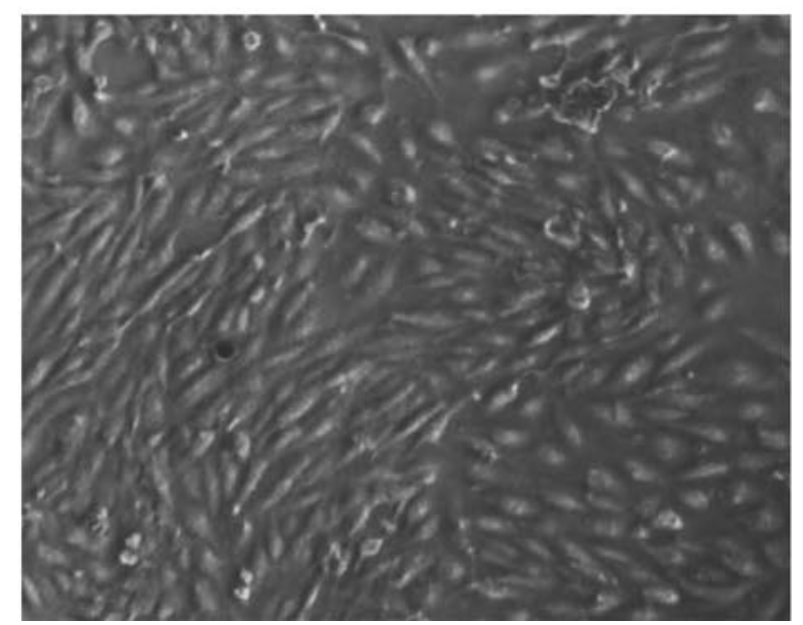

E

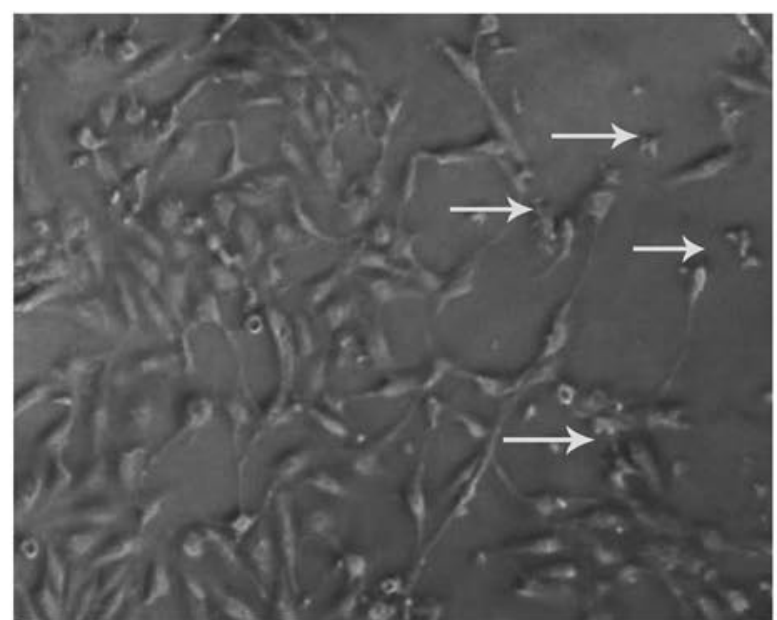

Figure 1. Cell viability of ARPE-19 cells assessed by MTT assay at various (A) ultrasound intensities, (B) exposure durations and (C) microbubble (MB) concentrations. The data indicated that an ultrasound intensity of 1 and $2 \mathrm{~W} / \mathrm{cm}^{2}$, duration of 60 and $120 \mathrm{sec}$, MB concentration of $20 \%$, and $50 \%$ duty cycle were the optimal conditions for the mediation of gene transfection to ARPE-19 cells ( $\left.{ }^{*} \mathrm{p}<0.05\right)$. (D) Phase-contrast image of ARPE-19 cells immediately after ultrasound-targeted microbubble destruction (UTMD) (1 and $2 \mathrm{~W} / \mathrm{cm}^{2}, 60$ and $120 \mathrm{sec}, 20 \% \mathrm{MBs}$, 50\% duty cycle). No cell damage was apparent. (E) Phasecontrast image of ARPE-19 cells immediately after UTMD (3 W/cm², $60 \mathrm{sec}, 100 \% \mathrm{MBs}, 50 \%$ duty cycle). Cell damage was apparent in many cells (arrows). (D and E, magnification $\mathrm{x} 100$ ). Data are presented as the means $\pm \mathrm{SD}$ of three independent experiments.

\section{Results}

Effect of ultrasound-targeted microbubble destruction on cell viability. The effects of UTMD on the viability of ARPE-19 cells are shown in Fig. 1. When the duty cycle was set at $50 \%$ with a $20 \% \mathrm{MB}$ concentration, the increase in US intensity (from 1 to $3 \mathrm{~W} / \mathrm{cm}^{2}$ ) and duration (from 60 to $240 \mathrm{sec}$ ) resulted in decreased cell viability. Cell viability was lowest in the $3 \mathrm{~W} /$ $\mathrm{cm}^{2}$ group $(74.58 \pm 10.46 \%)$ and the 4 min group $(72.93 \pm 8.33 \%)$. No significant difference was found between the $1 \mathrm{~W} / \mathrm{cm}^{2}$ and $2 \mathrm{~W} / \mathrm{cm}^{2}$ groups $(97.07 \pm 10.70$ vs. $91.29 \pm 2.62 \%)$, nor between the $1 \mathrm{~min}$ and the $2 \mathrm{~min}$ groups $(91.29 \pm 2.62$ vs. $88.75 \pm 7.59 \%)$ (Fig. $1 \mathrm{~A}$ and B). With a $2 \mathrm{~W} / \mathrm{cm}^{2}$ intensity and $60-\mathrm{sec}$ duration, the increase in MB concentration (from 20 to 100\%) resulted in an increase in cell mortality (Fig. 1E). Cell viability was lowest in the $100 \% \mathrm{MB}$ concentration group $(60.58 \pm 7.91 \%)$, and there was significant difference between the $20 \%$ and the $50 \% \mathrm{MB}$ concentration groups $(91.29 \pm 2.62$ vs. $77.97 \pm 2.96 \%)$ (Fig. 1C). Thus, an MB concentration of $20 \%$, US intensity of
1 and $2 \mathrm{~W} / \mathrm{cm}^{2}$, duration of 60 and $120 \mathrm{sec}$ and $50 \%$ duty cycle were determined to be the optimal conditions for the mediation of gene transfection to ARPE-19 cells (Fig. 1D).

Gene transfer by microbubbles, ultrasound and ultrasoundtargeted microbubble destruction. No improvement in transgene expression was observed in the $\mathrm{R}+\mathrm{MB}$ and $\mathrm{P}+\mathrm{MB}$ groups. Compared to the $\mathrm{R}$ and $\mathrm{P}$ alone groups, the $\mathrm{R}+\mathrm{US}$ $(21.47 \pm 0.53$ vs. $18.23 \pm 0.65 \%)$ and P+US $(1.06 \pm 0.13 \%$ vs. 0$)$ groups showed a weak but non-significant tendency to improve transgene expression. The ratio of EGFP-positive cells was significantly higher in the $\mathrm{R}+\mathrm{US}+\mathrm{MB}$ and $\mathrm{P}+\mathrm{US}+\mathrm{MB}$ groups (1.5 to 2-fold and 10 to 15 -fold, respectively) compared to the US alone groups under any of the following experimental conditions: $1 \mathrm{~W} / \mathrm{cm}^{2}, 60 \mathrm{sec}, 50 \%$ duty cycle, $20 \% \mathrm{MB}$ concentration; $1 \mathrm{~W} / \mathrm{cm}^{2}, 120 \mathrm{sec}, 50 \%$ duty cycle, $20 \% \mathrm{MB}$ concentration; $2 \mathrm{~W} / \mathrm{cm}^{2}$, $60 \mathrm{sec}, 50 \%$ duty cycle, $20 \% \mathrm{MB}$ concentration; $2 \mathrm{~W} / \mathrm{cm}^{2}, 120 \mathrm{sec}, 50 \%$ duty cycle, $20 \% \mathrm{MB}$ concentration (Fig. 2A and B). 
A
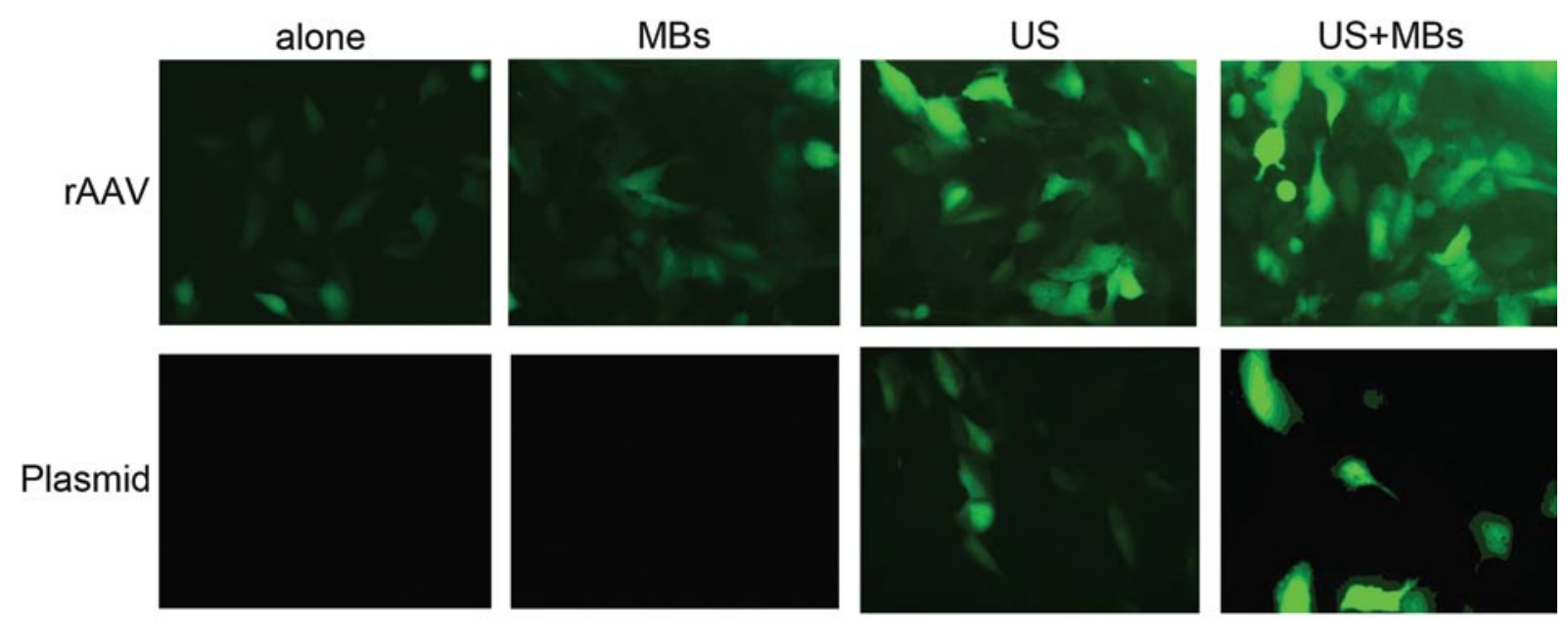

B

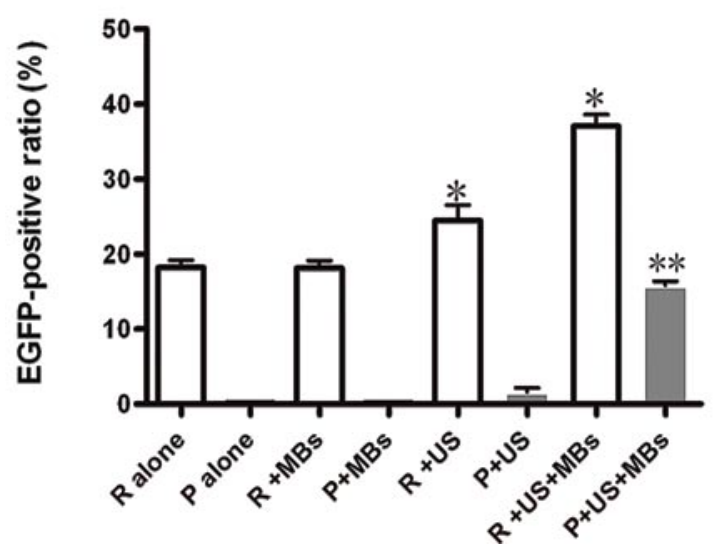

Figure 2. Transfection efficiency of recombinant adeno-associated virus (rAAV) and plasmid in ARPE-19 cells alone, with microbubbles (MBs), with ultrasound, and with ultrasound-targeted microbubble destruction (UTMD). (A) EGFP expression in ARPE-19 cells observed $48 \mathrm{~h}$ after transfection with rAAV2-EGFP and pEGFP-N1 (magnification x400). (B) EGFP-positive rate of ARPE-19 cells analyzed by flow cytometry $48 \mathrm{~h}$ after transfection with rAAV2-EGFP and pEGFP-N1 (** $<0.01$ and ${ }^{*} \mathrm{p}<0.05$, respectively). In all the experiments, the ARPE-19 cells were transfected with rAAV2-EGFP at a concentration of $1 \times 10^{3} \mathrm{vg} / \mathrm{cell}$ and with pEGFP-N1 at $10 \mu \mathrm{g} / \mathrm{well}$. Data are presented as the means $\pm \mathrm{SD}$ of three independent experiments.

Optimization of ultrasound-targeted microbubble destruction parameters in the recombinant adeno-associated virus- and plasmid-mediated gene transfection. To identify the optimal conditions for transferring genes by UTMD in the R+US+MB and $\mathrm{P}+\mathrm{US}+\mathrm{MB}$ groups, the following three parameters were examined:

Microbubble concentration. Four concentrations of MBs $(13.3,20,26.7$ and $33.3 \%)$ in the R+US+MB group were examined under conditions of $1 \mathrm{~W} / \mathrm{cm}^{2}$ US intensity, 60-sec duration and $50 \%$ duty cycle. Three concentrations of MBs, $(20,50$ and $100 \%)$ in the $\mathrm{P}+\mathrm{US}+\mathrm{MB}$ group were examined under the conditions of $2 \mathrm{~W} / \mathrm{cm}^{2}$ US intensity, 60 sec-duration and $50 \%$ duty cycle. In both groups, the EGFP-positive ratio was highest in cells treated by US with an MB concentration of $20 \%$ (Fig. 3A and B). Thus, a 20\% MB concentration was preferable.

Ultrasound intensity. US intensities of 1,2 and $3 \mathrm{~W} / \mathrm{cm}^{2}$ were examined under conditions of $50 \%$ duty cycle, $60-\mathrm{sec}$ duration and $20 \% \mathrm{MB}$ concentration in the R+US+MB and $\mathrm{P}+\mathrm{US}+\mathrm{MB}$ groups. The EGFP-positive ratio was smaller at US intensities of $3 \mathrm{~W} / \mathrm{cm}^{2}(32.92 \pm 0.97 \%)$ compared to 1 and $2 \mathrm{~W} / \mathrm{cm}^{2}$. No significant difference between the EGFP-positive ratio under 1 and the $2 \mathrm{~W} / \mathrm{cm}^{2}$ conditions $(37.05 \pm 0.55$ vs. $35.74 \pm 0.42 \%$, respectively) was found in the R+US+MB group

(Fig. 3C). However, in the P+US+MB group, an increase in US intensity resulted in an increase in the EGFP-positive ratio $\left(5.77 \pm 0.67,15.81 \pm 1.70\right.$ and $20.86 \pm 2.63 \%$ for 1,2 and $3 \mathrm{~W} / \mathrm{cm}^{2}$, respectively) (Fig. 3D). Taking into consideration the effect of UTMD on cell viability, US intensities of $1 \mathrm{~W} / \mathrm{cm}^{2}$ in group $\mathrm{R}+\mathrm{US}+\mathrm{MB}$ and $2 \mathrm{~W} / \mathrm{cm}^{2}$ in group $\mathrm{P}+\mathrm{US}+\mathrm{MBs}$ were selected.

Exposure duration. US exposure durations of 60 and $120 \mathrm{sec}$ were examined under conditions of $1 \mathrm{~W} / \mathrm{cm}^{2}, 50 \%$ duty cycle and $20 \% \mathrm{MB}$ concentration in the R+US+MB group and under conditions of $2 \mathrm{~W} / \mathrm{cm}^{2}, 50 \%$ duty cycle and $20 \% \mathrm{MB}$ concentration in the P+US+MB group. The EGFPpositive ratio was significantly higher with a 60 -sec duration than with a 120 -sec duration $(37.05 \pm 0.55$ vs. $28.13 \pm 0.67 \%$ in group R+US+MBs and $15.81 \pm 1.70$ vs. $11.31 \pm 1.99 \%$ in group P+US+MBs) (Fig. 3E and F). Consequently, an exposure duration of $60 \mathrm{sec}$ was determined to be appropriate in both groups.

\section{Discussion}

To date, the viral gene vector $\mathrm{rAAV}$ and non-viral gene vector plasmids have been extensively employed in gene modification for curing certain inherited or acquired retinal disorders. AAV is a single-stranded DNA-containing defective parvovirus. 
A

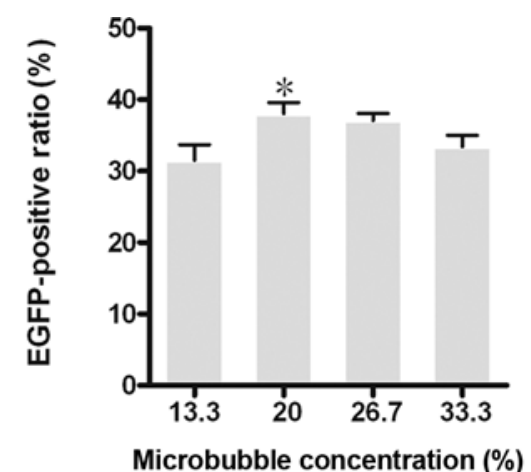

Microbubble concentration (\%)
B
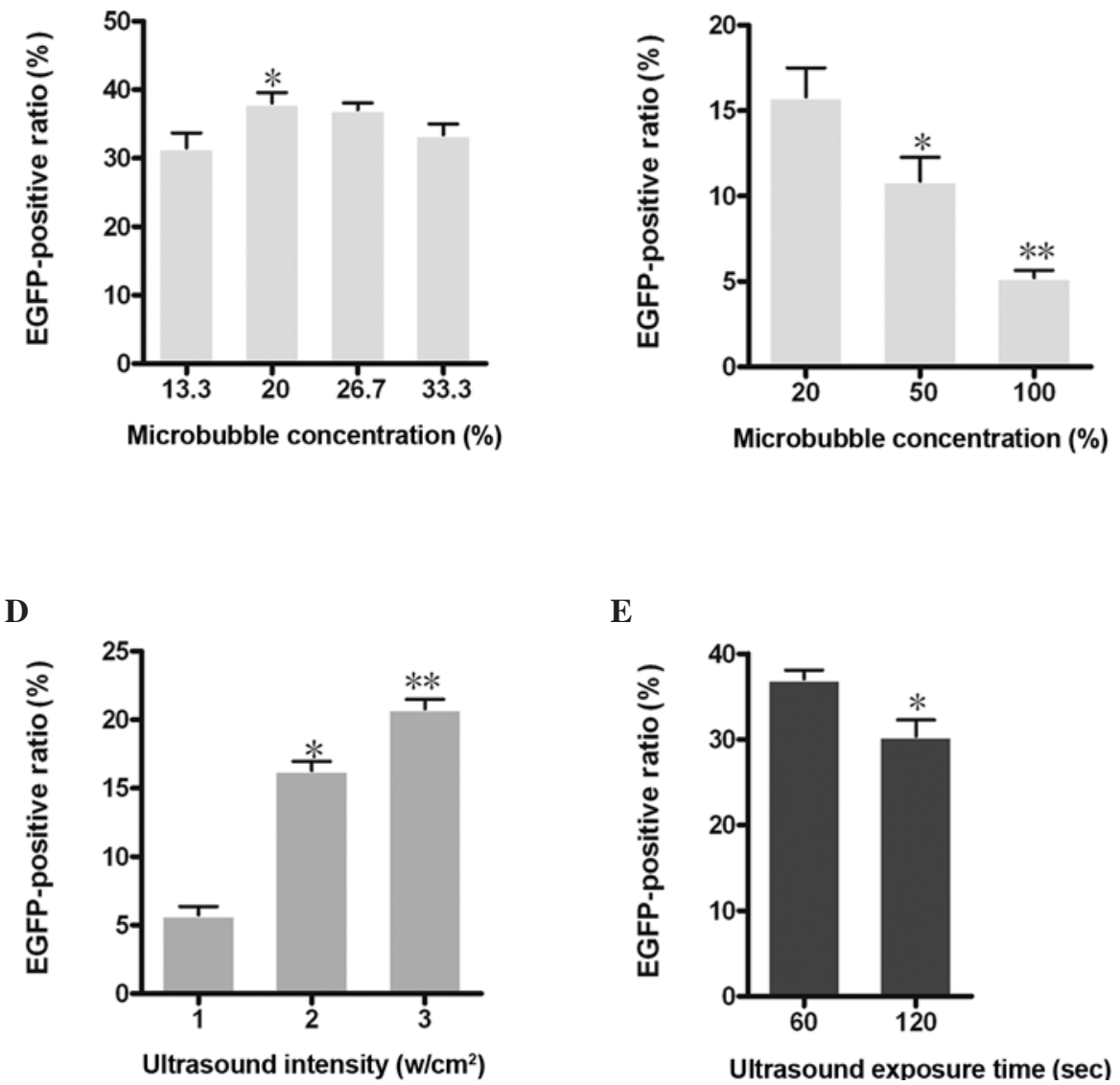

$\mathbf{E}$

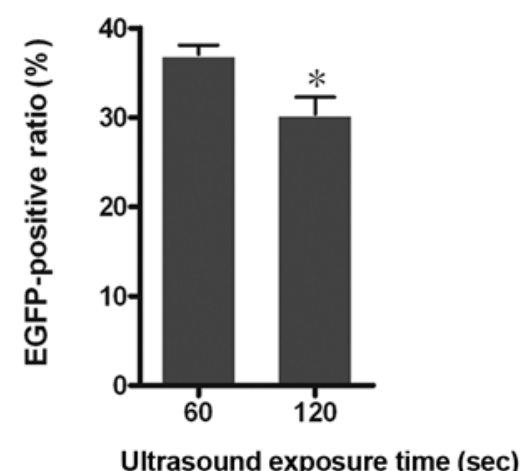

C

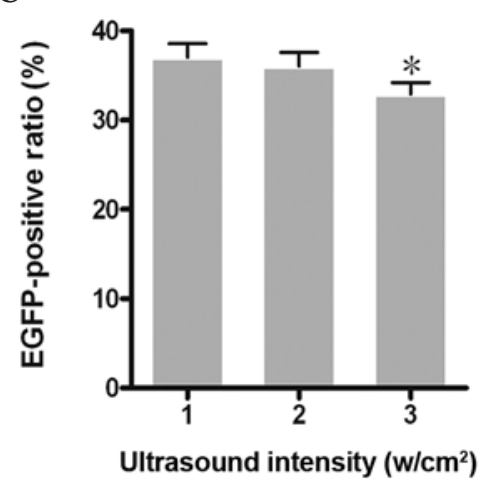

F

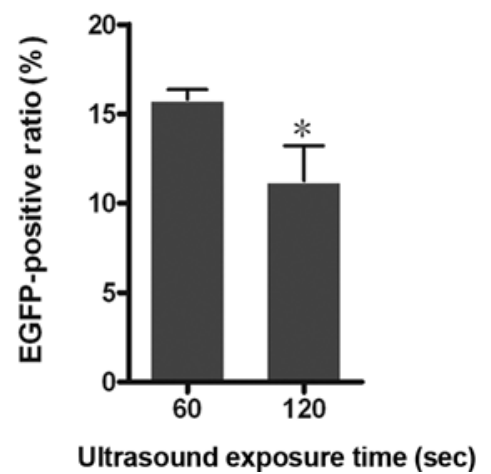

Figure 3. Gene transfer by ultrasound-targeted microbubble destruction (UTMD) under various conditions. Flow cytometry was used to examine the EGFPpositive ratio $48 \mathrm{~h}$ after transfection with: various concentrations of microbubbles and (A) rAAV2-EGFP and (B) pEGFP-N1; various ultrasound intensities and (C) rAAV2-EGFP and (D) pEGFP-N1; various ultrasound exposure durations and (E) rAAV2-EGFP and (F) pEGFP-N1 (** $<0.01$ and *p<0.05, respectively). In all the experiments, the ARPE-19 cells were transfected with rAAV2-EGFP at a concentration of $1 \mathrm{x} 10^{3} \mathrm{vg} / \mathrm{cell} \mathrm{and}$ with pEGFP-N1 at $10 \mu \mathrm{g} / \mathrm{well}$. Data are presented as the means \pm SD of three independent experiments.

Lack of efficiency in genome conversion is an obstacle to gene transfection, limiting its therapeutic effects. Several studies have found that a variety of biological, chemical and physical events, such as co-transfection of target cells with a helper virus or adenovirus (3), treatment with hydroxyurea or etoposide $(12)$, or ultraviolet $(13,14)$ or $\gamma$-ray irradiation $(15)$, can greatly enhance the efficiency of AAV-mediated transduction, presumably by catalyzing genomic conversion. However, these techniques may have marked adverse effects, such as innate host antiviral immune responses, cell toxicity and tissue damage. Gene delivery with plasmid vectors is highly inefficient unless the DNA is associated with other molecules and/or physical energy is applied to aid cell entry, for example through electroporation, gene gun or hydrodynamic pressure (16). These techniques often cause substantial tissue damage, making them inappropriate for clinical application.

US is widely used for clinical imaging, and its safety has been reliably established. Recent studies have demonstrated that UTMD can be used to enhance adenoviral or plasmid transgene transduction efficiency, reducing their concentrations and directing tissue expression of adenoviral or plasmid transgenes to a specific organ $(17,18)$. However, little research has been reported regarding UTMD enhanced rAAV- or plasmidmediated gene transfection into RPE cells. The detailed mechanisms of UTMD involvement in gene transfection have yet to be fully explained. It is thought that the bioeffects of UTMD, such as cavitation, thermal effect, radiation force and chemical effect combined, may result in permeability changes to the cell membrane, therefore leading to the increased uptake of transgenes $(10,19,20)$. In addition to permeabilization of the cell membrane, locally and momentarily-generated energy released by the collapse of MBs acts as a motivational force, overcoming the physical obstacle of the plasma membrane. Thus, foreign genes of interest can pass into the cell, and the intracellular shock wave can encourage the vector DNA or RNA to exit the endosome and enter the nucleus.

The results presented here suggest that higher rAAV and plasmid transfection efficiency can be obtained in ARPE-19 cells by UTMD, though not by US or MBs alone. To establish the optimal conditions for UTMD in the rAAV-EGFP and pEGFP-N1 groups, the effects of UTMD on ARPE-19 cell viability were initially assessed. Three UTMD variables, MB concentration, US intensity and US exposure duration, were sequentially examined, and the optimal conditions that could be safely applied for gene transfection to ARPE-19 cells were obtained. Taking into consideration gene transfection efficiency and cell viability, the optimal UTMD conditions were $1 \mathrm{~W} / \mathrm{cm}^{2}$ US intensity, $60-\mathrm{sec}$ duration, $50 \%$ duty cycle and $20 \% \mathrm{MB}$ 
concentration in the rAAV-EGFP group, and $2 \mathrm{~W} / \mathrm{cm}^{2} \mathrm{US}$ intensity, 60 -sec duration, $50 \%$ duty cycle and $20 \%$ MB concentration in the pEGFP-N1 group.

Although the transfection efficiency of plasmid enhanced by UTMD was markedly elevated compared to that of plasmid alone (from 0 to $>10 \%$ ), it was still far below the threshold needed for efficient gene modification, and was not further elevated by increasing the concentration of plasmid. For example, when the concentration of plasmid was increased from 6 to $10 \mu \mathrm{g} /$ well, transfection efficiency only increased from $12.58 \pm 1.75$ to $15.81 \pm 1.70 \%$ (data not shown). In contrast, the transfection efficiency of rAAV enhanced by UTMD was just below or at the level required for gene therapy. Moreoever, increasing the concentration of rAAV improved therapeutic efficacy. For example, the transfection efficiency of rAAV treated by UTMD increased from $37.05 \pm 0.55 \%$ to $53.23 \pm 1.09 \%$ when the MOI of rAAV was increased from $1 \times 10^{3} \mathrm{vg} / \mathrm{cell}$ to $1 \times 10^{4} \mathrm{vg} / \mathrm{cell}$ (data not shown). Therefore, rAAV may be an appropriate gene vector for use with UTMD treatment in retinal gene modification.

The difference in the effect of UTMD on the transfection efficiency of rAAV-EGFP and pEGFP-N1 in ARPE-19 cells is primarily due to the different transfection mechanisms of AAV and plasmid. AAV initiatively transfers into ARPE-19 cells by adhesion to their surface receptors, while plasmid is only transferred into ARPE-19 cells passively by other materials or by energy. Additionally, AAV and plasmid have different biological characteristics, such as their molecular weight, distribution of microstructures and trait of CHARGE, leading to different modalities and results of interaction between ARPE-19 cells and rAAV-EGFP or pEGFP-N1, and thus different transfection efficiency. The subtle mechanisms underlying these phenomena are complicated and require further elucidation.

In summay, our in vitro findings demonstrate that UTMD is capable of significantly enhancing the transfection efficiency of rAAV and plasmid in ARPE-19 cells without adverse effects on cell viability. In ARPE-19 cells, the optimal UTMD conditions for mediating rAAV and plasmid transfection are, respectively, $1 \mathrm{~W} / \mathrm{cm}^{2}$ US intensity, $60-\mathrm{sec}$ duration, $50 \%$ duty cycle and $20 \% \mathrm{MB}$ concentration, and $2 \mathrm{~W} / \mathrm{cm}^{2} \mathrm{US}$ intensity, 60-sec duration, 50\% duty cycle and 20\% MB concentration. In retinal gene modification, rAAV may be an appropriate gene vector for use with UTMD.

\section{Acknowledgements}

This work was supported by National Natural Science Foundation of China (grant no. 30772369). The authors gratefully acknowledge the entire staff at the Experimental Research Center of Shanghai Jiaotong University Affiliated First People's Hospital for technical assistance and helpful discussion.

\section{References}

1. Yaji N, Yamato M, Yang J, Okano T and Hori S: Transplantation of tissue-engineered retinal pigment epithelial cell sheets in a rabbit model. Biomaterials 30: 797-803, 2009.

2. Hoppe G, Marmorstein AD, Pennock EA and Hoff HF: Oxidized low density lipoprotein-induced inhibition of processing of photoreceptor outer segments by RPE. Invest Ophthalmol Vis Sci 42: 2714-2720, 2001.

3. Wu JH, Zhang SH, Wu XB, Dong X, Xu P, Liu X, Li C and Huang Q: Enhanced transduction and improved photoreceptor survival of retinal degeneration by the combinatorial use of rAAV2 with a lower dose of adenovirus. Vis Res 48: 1648-1654, 2008.

4. Thumann G, Hoffmann S and Hinton DR: Cell biology of the retinal pigment epithelium. In: Retina. 4th edition. Ryan SJ (ed). Elsevier Mosby, pp137-152, 2006.

5. Alexander JJ and Hauswirth WW: Adeno-associated viral vectors and the retina. Adv Exp Med Biol 613: 121-128, 2008.

6. Daya S and Berns KI: Gene modification using adeno-associated virus vectors. Clin Microbiol Rev 21: 583-593, 2008.

7. Somiari S, Glasspool-Malone J, Drabick JJ, Gilbert RA, Heller R, Jaroszeski MJ and Malone RW: Theory and in vivo application of electroporative gene delivery. Mol Ther 2: 178-187, 2000.

8. Hosseinkhani H, Aoyama T, Ogawa O and Tabata Y: Ultrasound enhances the transfection of plasmid DNA by non-viral vectors. Curr Pharmaceut Biotechnol 4: 109-122, 2003.

9. Otani K, Yamahara K, Ohnishi S, Obata H, Kitamura S and Nagaya N: Nonviral delivery of siRNA into mesenchymal stem cells by a combination of ultrasound and microbubbles. J Control Release 133: 146-153, 2009.

10. Mukherjee D, Wong J, Griffin B, Ellis SG, Porter T, Sen S and Thomas JD: Ten-fold augmentation of endothelial uptake of vascular endothelial growth factor with ultrasound after systemic administration. J Am Coll Cardiol 35: 1678-1686, 2000.

11. Zderic V, Vaezy S, Martin RW and Clark JI: Ocular drug delivery using 20-kHz ultrasound. Med Biol 28: 823-829, 2002.

12. Russell DW, Alexander IE and Miller AD: DNA synthesis and topoisomerase inhibitors increase transduction by adeno-associated virus vectors. Proc Natl Acad Sci 92: 5719-5723, 1995.

13. Ferrari FK, Samulski T and Shenk T: Second strand synthesis is a rate-limiting step for efficient transduction by recombinant adeno-associated virus vectors. J Virol 70: 3227-3234, 1996.

14. Duan D, Yue Y, Yan Z and McCray PB Jr: Polarity influences the efficiency of recombinant adeno-associated virus infection in differentiated airway epithelia. Hum Gene Ther 9: 2761-2776, 1998.

15. Alexander IE, Russell DW, Spence AM and Miller AD: Effects of gamma irradiation on the transduction of dividing and non-dividing cells in brain and muscle of rats by recombinant adeno-associated virus vectors. Hum Gene Ther 7: 841-850, 1996.

16. Niidome $\mathrm{T}$ and Huang L: Gene modification progress and prospects: nonviral vectors. Gene Ther 9: 1647-1652, 2002.

17. Howard CM, Forsberg F, Minimo C, Liu JB, Merton DA and Claudio PP: Ultrasound guided site specific gene delivery system using adenoviral vectors and commercial ultrasound contrast agents. J Cell Physiol 209: 413-421, 2006.

18. Tsunoda S, Mazda O, Oda Y, Iida Y, Akabame S, Kishida T, Shin-Ya M, Asada H, Gojo S, Imanishi J, Matsubara H and Yoshikawa T: Sonoporation using microbubble BR14 promotes pDNA/siRNA transduction to murine heart. Biochem Biophys Res Commun 336: 118-127, 2005.

19. Juffermans LJ, Dijkmans PA, Musters RJ, Visser CA and Kamp O: Transient permeabilization of cell membranes by ultrasoundexposed microbubbles is related to formation of hydrogen peroxide. Am J Physiol Heart Circ Physiol 291: H1595-H1601, 2006.

20. Basta G, Venneri L, Lazzerini G, Pasanisi E, Pianelli M, Vesentini N, Del Turco S, Kusmic C and Picano E: In vitro modulation of intracellular oxidative stress of endothelial cells by diagnostic cardiac ultrasound. Cardiovasc Res 58: 156-161, 2003. 